\title{
KRONIEK
}

\section{De toegevoegde waarde van criminologie in terrorismeonderzoek}

\author{
Marieke Liem \& Edwin Bakker
}

\begin{abstract}
Terrorisme kan bezien worden als een extreme vorm van (gewelddadig) crimineel gedrag. Tegen deze achtergrond is het noodzakelijk om kennis uit de criminologie te vergaren, om zo terrorismeonderzoek te versterken. In dit overzicht beschrijven de auteurs hoe criminologische theorieën een significante bijdrage kunnen leveren in het duiden van de onderliggende oorzaken van terrorisme. Eerdere bijdragen van de criminologie aan terrorismeonderzoek waren voornamelijk theorieverbredend opgesteld, zoals de routine-activiteitentheorie, de rationele-keuzetheorie en de strain-theorie, maar het ontbrak bij deze exercities aan empirische gegevens. Er is op heden weinig bekend over empirische bruikbaarheid en toepasbaarheid van andere criminologische theorieën, waarbij vooral desistance-theorieën nadere aandacht verdienen. Voor een beter en breder begrip van terrorisme alsook een beter contraterrorismebeleid dienen empirische data verzameld te worden. Zo kunnen terrorismeonderzoekers, in nauwe samenwerking met criminologen, de noodzakelijke empirische en theoretische verdieping aanbrengen in dit relatief onontgonnen veld.
\end{abstract}

\section{Inleiding}

Terrorisme is vrijwel dagelijks in het nieuws naar aanleiding van aanslagen door groeperingen als Islamitische Staat, Boko Haram en Al Qaida, of het gebruik van geweld door eenlingen. Denk bij dat laatste aan de aanslagen in Nice, Berlijn, Manchester en Marseille, waarbij in Europa in de afgelopen jaren tientallen doden vielen. ${ }^{1}$ In deze bijdrage staan we allereerst stil bij de status quo van terrorismeonderzoek. Hoewel diverse academische disciplines zich over het fenomeen terrorisme hebben gebogen, staat een criminologische benadering van dit gewelddadige gedrag nog in de kinderschoenen. In dit overzicht beogen we daarom te beschrijven hoe terrorisme verklaard kan worden door een criminologische lens, en een aantal suggesties te doen hoe criminologische benaderingen van grote toegevoegde waarde kunnen zijn in (toekomstig) onderzoek naar terrorisme. Tot slot zullen we - gezien de recente aanslagen in Europa - nader aandacht besteden aan een specifieke vorm van terrorisme, te weten lone actor-terrorisme.

1 Voor een overzicht van terroristische aanslagen door eenlingen in Europa, zie de Global Terrorism Database van Maryland University en de Terrorism Situation and Trend Reports (TE-SAT) van Europol. 


\section{Terrorisme en onderzoek naar 'lone actor'-terrorisme}

\section{Terrorisme}

Voornoemde geweldsdaden worden terroristisch genoemd omdat de daders pogen daarmee de publieke opinie en politieke besluitvorming te beïnvloeden. Artikel 83a van het Nederlandse Wetboek van Strafrecht spreekt van een 'terroristisch oogmerk'. ${ }^{2}$ De Nationaal Coördinator Terrorismebestrijding en Veiligheid (NCTV) spreekt van terroristische aanslagen wanneer sprake is van 'het uit ideologische motieven dreigen met, voorbereiden of plegen van op mensen gericht ernstig geweld, dan wel daden gericht op het aanrichten van maatschappijontwrichtende zaakschade, met als doel maatschappelijke veranderingen te bewerkstelligen, de bevolking ernstige vrees aan te jagen of politieke besluitvorming te beïnvloeden'. ${ }^{3}$ Ook veel academische definities benadrukken de combinatie van geweld, ideologische motieven en politieke doelen. ${ }^{4}$

Bij deze definities is het maatschappelijke en politieke aspect cruciaal. Mede tegen die achtergrond wordt er door academici en beleidsmakers vaak een onderscheid gemaakt tussen typen terrorisme op basis van de ideologische motieven van de daders. Een algemeen gebruikte categorisering van terrorisme is die welke door Europol wordt gehanteerd en onderscheid maakt tussen jihadistisch terrorisme, etnonationalistisch en separatistisch terrorisme, links en anarchistisch terrorisme, rechts terrorisme en tot slot het zogeheten 'single issue'-terrorisme (Europol, 2017). Bij dit laatste type gaat het om personen of groeperingen die slechts op een specifiek doel gericht zijn, zoals het tegengaan van dierproeven, abortus of de uitzetting van illegalen.

Daarnaast wordt er in rapporten over en onderzoeken naar terrorisme een onderscheid gemaakt tussen typen terrorisme op basis van de modus operandi. Denk aan de termen zelfmoordterrorisme, $C B R N$-terrorisme ${ }^{5}$ en lone actor-terrorisme. ${ }^{6}$ $\mathrm{Bij}$ het laatste gaat het om aanslagen door eenlingen of door kleine groepen. In een groot Europees onderzoeksproject naar deze vorm van terrorisme wordt gesproken van lone actor-terrorisme als sprake is van ' $t$ the threat or use of violence by a single perpetrator (or small cell), not acting out of purely personal material reasons, with the aim of influencing a wider audience, and who acts without any direct support in the planning, preparation and execution of the attack, and whose decision to act is not directed by any group or other individuals

2 'Onder terroristisch oogmerk wordt verstaan het oogmerk om de bevolking of een deel der bevolking van een land ernstige vrees aan te jagen, dan wel een overheid of internationale organisatie wederrechtelijk te dwingen iets te doen, niet te doen of te dulden, dan wel de fundamentele politieke, constitutionele, economische of sociale structuren van een land of een internationale organisatie ernstig te ontwrichten of te vernietigen' (art. 83a van het Wetboek van Strafrecht).

3 Zie www.nctv.nl/organisatie/ct/terrorismebestrijding/index.aspx.

4 Tegen deze achtergrond hanteren we de omschrijving van terrorisme in art. 83a van het Wetboek van Strafrecht als werkdefinitie van terrorisme.

5 CBRN staat voor chemische, biologische, radiologische en nucleaire middelen.

6 Hoewel 'lone actor'-terrorisme ook wel bekendstaat als 'lone wolf'-terrorisme, geven wij de voorkeur aan de term lone actor-terrorisme om eventuele glorificatie en romantisering die in de term 'lone wolf' besloten liggen, te vermijden. 
(although possibly inspired by others)' (Ellis e.a., 2016). Volgens deze definitie verschillen lone actor-terroristen van 'conventionele' gewelddadige criminelen omdat ze niet uit zijn op persoonlijk en materieel gewin en het geweld tegen slachtoffers een middel is om een publiek te bereiken en geen doel op zich is.

\section{Raakvlak met criminologie}

\section{Criminologische theorieën}

Hoewel er zich in de afgelopen twintig jaar een explosieve groei heeft voorgedaan in terrorismeonderzoek op het gebied van sociale en gedragskundige wetenschappen, is dit onderzoek met name gecentreerd op het terrein van de politicologie en (sociale) psychologie. Zo laten recente overzichten door bijvoorbeeld LaFree en Ackerman (2009) en Rosenfeld (2014) zien dat empirische toepassingen van criminologische theorieën op terrorisme tot nu toe zeer schaars zijn. Dit is op zich, zoals de criminologen Joshua Freilich en Gary LaFree (2015) stellen, verbazingwekkend, aangezien terrorisme als gedraging een criminele gedraging betreft. Daarnaast kan gesteld worden dat 'conventionele' criminelen en terroristen veel overeenkomsten vertonen met betrekking tot sociaal-demografische karakteristieken: de meerderheid van beide groepen wordt gevormd door jonge mannen (LaFree \& Ackerman, 2009; Young \& Kearns, 2017). In de derde plaats vormt het bestuderen van het effect van justitiële interventies, zoals gevangenisstraf, een belangrijke overeenkomst. Zo wordt beargumenteerd dat gevangenissen niet alleen gezien kunnen worden als 'schools of crime', maar ook als 'universiteiten in terrorismetraining' (Useem \& Clayton, 2009). Criminologische theorieën zouden tegen deze achtergrond een significante bijdrage kunnen leveren in het inzichtelijk maken en duiden van oorzaken van terrorisme (Agnew, 2010; LaFree \& Dugan, 2009; LaFree \& Gruenewald, 2018).

Desalniettemin heeft tot nu toe slechts een aantal criminologen zich expliciet gewaagd aan de toepassing van criminologische theorieën op terroristische gedragingen. Zo beschouwde Mark Hamm (2007) terrorisme vanuit de routine-activiteitentheorie, op basis waarvan terrorisme kan worden bezien als een resultaat van het samenkomen van een gemotiveerde dader, een geschikt slachtoffer en een afwezigheid van supervisie (Cohen \& Felson, 1979). Tevens wees hij op interventiemogelijkheden, gericht op de dagelijkse routine van terroristen en hun slachtoffers (Hamm, 2007). Een andere veelgebruikte theorie in dit verband vormt de rationele-keuzetheorie. Vanuit dit perspectief komen terroristische gedragingen tot stand wanneer terroristen de kosten van hun handelen afwegen tegen de baten, ofwel de kans om gepakt te worden en de hoogte van de straf tegen intern, bijvoorbeeld financiële compensatie, of extern profijt, bijvoorbeeld in de vorm van politieke erkenning (LaFree \& Dugan, 2009). Deze benadering staat tevens aan de basis van veel contraterrorismemaatregelen die beogen de 'kosten' van terrorisme dusdanig hoog te maken dat het voor potentiële daders onaantrekkelijk wordt om dergelijk gedrag uit te voeren. Hierbij valt te denken aan het vergroten van de pakkans en het verhogen van de (gevangenis)straf bij arrestatie. Deze theorie lijkt echter niet volledig toepasbaar wanneer we kijken 
naar bepaalde vormen van terrorisme, zoals zelfmoordterrorisme, waarin de potentiële dader bereid is het eigen leven op te offeren om een bepaald doel te bereiken. Hoewel onderzoek heeft laten zien dat zelfmoordterroristen hun daden soms uitstellen om de pakkans te verkleinen en de kans op een geslaagde aanslag te vergroten, lijken het vergroten van de pakkans en het verhogen van straffen tot op heden geen doorslaggevend effect te hebben op het voorkomen van terrorisme (LaFree \& Dugan, 2009; Roberts, 2007).

Daarnaast heeft Robert Agnew (2010) in een theoretische verhandeling de general strain-theorie toegepast op terrorisme. Strains verwijzen, kort gezegd, naar negatieve gebeurtenissen of condities, waaronder een kwalijke behandeling door anderen (ontvangen van iets negatiefs), het verlies van een gewaardeerd goed (verlies van iets positiefs), of het gebrek aan de mogelijkheid om bepaalde doelen te bereiken (Agnew, 1992). De kans op crimineel gedrag neemt toe met een grotere impact van de strain, een grotere onrechtvaardigheid van de strain, gepaard gaande met een lage zelfcontrole, en een druk of kans om op criminogene wijze om te gaan met de betreffende strain. In zijn theoretische uitbreiding van de strain-theorie naar terrorisme stelt Agnew (2010) dat de kans op terroristische gedragingen toeneemt bij een hoge mate van impact (zoals verlies van dierbaren, bedreiging van kernwaarden en bedreiging van fysieke integriteit en veiligheid), een langdurige blootstelling aan de strain zonder zicht op een einde en een wijdverspreide aard van de strain (zoals een impact op velen in de gemeenschap), en wanneer de strain wordt veroorzaakt door machtige 'anderen', en deze strain wordt gezien als onrechtvaardig. Een manier om deze collectieve strain het hoofd te bieden, zo beargumenteert Agnew, is door aansluiting bij een terroristische groep, die een collectieve respons tegen deze strains kan bieden. Marc Sageman (2008) is een van de weinigen die deze theorie expliciet heeft toegepast op terrorisme. In zijn studie naar jihadistische groepen vond hij dat 60 procent van de individuen zich aansloot bij een dergelijke groep in een land waar zij niet waren opgegroeid, en een bijkomende 20 procent tweede of derde generatie allochtonen met een moslimachtergrond betrof. Zo kan worden beargumenteerd dat de strain, die deze individuen ervaren door hun afkomst en gemarginaliseerde (immigranten)status, een verklarende factor kan vormen voor hun keuze tot lidmaatschap van dergelijke groepen (LaFree \& Dugan, 2009).

In Nederland sluit het onderzoek van Frank Bovenkerk en anderen, op het snijvlak van antropologie en criminologie, hier deels bij aan. Net als Sageman wijzen zij op het feit dat jihadistische terroristen in het Westen geen buitenstaanders of een 'extern probleem' zijn, omdat zij vaak in diezelfde westerse samenlevingen zijn opgegroeid. Bovenkerk en Vermeulen (2012) snijden daarnaast een belangrijk ander punt aan, namelijk de gevolgen voor zowel onderzoek als beleid als gevolg van een gebrek aan empirische data. In hun studie naar lokaal beleid tegen radicalisering en terrorisme zijn ze met name kritisch op het gebrek aan empirische onderbouwing voor het gevoerde (anti)radicaliseringsbeleid. Daarbij stellen ze dat dit ook niet onderbouwd kan zijn, simpelweg omdat het absolute aantal jihadistische terroristen dusdanig laag is, dat er nauwelijks iets algemeens te zeggen is over hun eigenschappen en radicaliseringsproces (Bovenkerk \& Vermeulen, 
2012). En daarmee zijn we tevens aangeland bij een van de belangrijkste tekortkomingen van onderzoek naar terroristische daders: het gebrek aan data.

\section{Empirisch onderzoek op het snijvlak van terrorisme en criminologie}

Benadrukt dient te worden dat voornoemde bijdragen aan inzichten in het fenomeen terrorisme voornamelijk theorieverbredend zijn opgesteld. We constateren tevens dat de bijdragen meestal geen empirische gegevens bevatten, op basis waarvan de betreffende theorie kan worden getest. Het aanwezige empirisch onderzoek is bovendien sterk gericht op jihadistisch terrorisme. Een voorbeeld hiervan is het onderzoek van De Bie e.a. naar de modus operandi van jihadistische netwerken in Nederland (De Bie e.a., 2015; De Bie, 2016). Vergeleken met de jihadistische vorm van terrorisme is er relatief weinig aandacht voor rechtsextremisme, linksextremisme of andere vormen van terroristisch geweld (Freilich e.a., 2009). Criminologisch onderzoek op het gebied van terrorisme is, kort samengevat, tot op heden schaars (LaFree, 2009; LaFree \& Dugan, 2009). Een van de redenen voor een dergelijk onderzoeksvacuüm ligt in het gebrek aan beschikbare data (Chermak e.a., 2012; Schuurman \& Eijkman, 2013). In criminologisch onderzoek wordt normaliter gebruik gemaakt van data uit een van de volgende bronnen, te weten registratiedata, zoals geregistreerd door de politie of andere partijen in de strafrechtsketen, slachtofferdata, zoals weergegeven in slachtofferenquêtes en grootschalige bevolkingsenquêtes, en tot slot zelfrapportagedata van daders van crimineel gedrag.

Geen van deze drie databronnen volstaat echter om een volledig en compleet beeld te krijgen, laat staan een accurate sample, van individuen of groepen verdacht van terrorisme, zoals Jessica Stern constateerde (Stern, 2009). Zo registreren politie en andere actoren in de strafrechtsketen weliswaar veel 'gewone' criminaliteit, zoals geweldsdelicten, diefstallen, enzovoort, maar vindt dergelijke registratie niet op eenzelfde wijze plaats op het gebied van terrorisme. Naast het gegeven dat vaak diverse organisaties betrokken zijn, die ieder op eigen wijze registreren, vallen terroristische daden veelal niet onder één noemer. Zo kan een terroristische daad worden geregistreerd als een levensdelict wanneer er een dode valt te betreuren, of als een brandstichting wanneer brand ontstaat als gevolg van een explosie. Uit eerder onderzoek blijkt dat de meeste Amerikaanse terrorismeverdachten niet officieel voor terrorisme worden vervolgd, maar voor aan terrorisme gerelateerde vergrijpen, zoals vuurwapenovertredingen of witwassen (Smith e.a., 2002). Op deze manier verdwijnt de gemeenschappelijke deler, namelijk terrorisme, in de registratiestatistieken.

Daarnaast zijn, zoals LaFree en Dugan (2009) aangeven, dergelijke door de overheid verzamelde data niet altijd even betrouwbaar gezien de politieke overwegingen die meespelen bij het definiëren en registreren van gedragingen als terrorismegerelateerd. Deze kwestie staat nog los van de toegankelijkheid van data, aangezien in veel landen terroristische vergrijpen worden geregistreerd door inlichtingendiensten, die in veel gebieden (gedeeltelijk) buiten de nationale strafrechtsketen - en dus ook de nationale criminaliteitsregistratie - opereren. Tevens, zo stellen LaFree en Dugan (2009), schieten slachtofferenquêtes als databron voor terrorisme vaak tekort, gezien de extreme zeldzaamheid van terroristische delic- 
ten vergelijkbaar met 'conventionele', meer gangbare vormen van criminaliteit. Bovendien hebben slachtoffers van terrorisme veelal niet eerder contact gehad met terroristische daders, of komen slachtoffers bij een terroristische daad om het leven, en komen daardoor per definitie niet voor in dergelijke enquêtes. Tot slot vormt zelfrapportagedata een mogelijke bron van informatie, maar gezien de drempels om in contact te komen met deze daderpopulatie, gepaard gaande met de bevinding dat (voormalig) terrorismeverdachten - met enkele uitzonderingen (zie bijvoorbeeld Elbers e.a., 2016; Schuurman, 2017) - vaak geen medewerking verlenen aan onderzoek, is deze databron niet in staat om een accuraat kwantitatief beeld te schetsen van de aard en omvang van terroristische gedragingen.

Een andere veelgenoemde reden is gelegen in het simpele feit dat terrorisme tot relatief recent geen acute bedreiging vormde voor westerse democratieën. Na de Oklahoma City-aanslag in 1995 en de aanslagen van 11 september 2001 volgde met name in de Verenigde Staten, maar ook in andere westerse landen een enorme toekenning van (Amerikaans) onderzoeksgeld, waaronder onderzoeksgeld naar criminologische benaderingen van terrorisme (LaFree, 2009).

\section{Onderzoek naar lone actor-terrorisme}

Gelet op de recente aanslagen door eenlingen in Europa krijgt het fenomeen lone actor-terrorisme de nodige aandacht van beleidsmakers en academici. Tegen deze achtergrond zullen we hier specifiek stilstaan bij dit type terroristisch geweld en de status quo van (criminologisch) onderzoek op dit gebied.

Veelgestelde vragen rond aanslagen door eenlingen hebben betrekking op de achtergrond en motieven van de daders en hun radicaliseringsproces. Europees onderzoek naar terroristische eenlingen kreeg een impuls na de aanslag in Noorwegen door de eenling Anders Breivik. Bij deze aanslag in juli 2011 kwamen maar liefst 77 mensen om het leven en raakten meer dan 300 personen gewond. Deze terroristische daad liet zien dat ook acties door eenlingen tot zeer veel slachtoffers kunnen leiden. Hoewel de aanslag door Breivik niet de eerste in zijn soort was, kreeg deze specifieke vorm van terrorisme tot dan toe amper aandacht in Europa. Een EU-onderzoeksproject naar terrorisme in het algemeen (TTSRL) besteedde in een deelstudie zijdelings aandacht aan het fenomeen. In deze studie, uitgevoerd in 2007 door het COT, werd door Ramon Spaaij e.a. onder meer gekeken naar de ontwikkeling van het aantal aanslagen door eenlingen. Een van de observaties was dat het, destijds, in de westerse wereld vooral ging om personen met een extreemrechtse en racistische achtergrond en een aantal gevallen van islamitische fundamentalisten, nationalisten en separatisten en 'single issue'-terroristen. Ook werd in het rapport geconstateerd dat bij een relatief groot deel van de aanslagen door eenlingen de precieze ideologische achtergrond onduidelijk is (COT, 2007). In een latere studie uit 2009 voegt Spaaij hieraan toe dat het fenomeen zich vaker voordoet in de Verenigde Staten dan welk land dan ook, en dat het aantal gevallen daar sinds de jaren tachtig duidelijk is toegenomen (Spaaij, 2009). Dit verklaart deels waarom er in de Verenigde Staten de afgelopen decennia relatief meer aandacht voor het fenomeen was. Aanslagen door (vermeende) eenlingen die tot meer onderzoek naar en beleid op lone actor-terrorisme leidden, waren de Oklahoma City bombing in 1985 door Timothy McVeigh, met meer dan 
150 dodelijke slachtoffers, de bombrieven aan onder meer universiteiten door de 'Unabomber' Ted Kaczynski, tientallen aanslagen door rechts-extremisten op minderheden, en aanslagen op abortusklinieken en de daar werkzame artsen.

Een van de belangrijkste onderzoekers in de Verenigde Staten op het gebied van terrorisme door eenlingen is Mark Hamm. Hij deed onder meer onderzoek naar radicalisering, de rechtse ondergrondse terroristische bewegingen en de 'Oklahoma bombing'. Andere Amerikaanse onderzoekers op dit gebied zijn Jessica Stern (2003), die in haar onderzoek naar terrorisme de nadruk legt op de motieven van individuele terroristen, onder wie religieus geïnspireerde terroristen, en Clark McCauley en Sophia Moskalenko (2014), die zich specifiek richtten op lone actor-terroristen en de relatie en ontwikkeling tussen radicale opinies en radicale acties bekeken. Jeff Gruenewald deed met anderen onder meer onderzoek naar patronen van lone actor-terrorisme in de Verenigde Staten (Smith e.a., 2014). Daarnaast vergeleek Gruenewald samen met Steven Chermak en Joshua Freilich (2013) de kenmerken van extreemrechtse daders met die van 'gewone' moordenaars. De afgelopen jaren werd ook onderzoek gedaan naar de rol van internet en sociale media rond dit fenomeen, onder anderen door Gabriel Weimann, Ramon Spaaij en Jason-Leigh Striegher (Weimann, 2012; Spaaij, 2012; Striegher, 2013). Het gebruik van informatietechnologie was ook een van de factoren die meegenomen werd in een uitgebreide studie naar de kenmerken van het sociale netwerk en antecedent gedrag van meer dan 100 Amerikaans lone actor-terroristen door Paul Gill, John Horgan en Paige Deckert (2014). Een van hun meest opvallende bevindingen was dat veel eenlingen zelden impulsief of plotseling tot hun daad kwamen, maar soms al jarenlang plannen daartoe hadden.

De bevindingen uit de Verenigde Staten in het algemeen en die uit het onderzoek van Paul Gill in het bijzonder werden meegenomen in twee grote recente EUonderzoeksprojecten die specifiek gericht waren op lone actor-terrorisme: PRIME - Predicting, Interdicting and Mitigating Extremism -, dat als doel had aanknopingspunten te vinden voor het voorkomen van en omgaan met zogeheten 'lone actor extremist events', ${ }^{7}$ en CLAT - Countering Lone Actor Terrorism: Data Collection \& Analysis -, dat specifiek gericht was op het creëren van een databestand met gevallen van lone actor terrorism in Europa. ${ }^{8}$ Daarmee droegen beide projecten bij aan het verzamelen van empirische gegevens en de mogelijkheid om die naast Amerikaanse gegevens en bevindingen te leggen. Deze onderzoeken sluiten aan bij de eerdere pogingen van Mark Hamm en Ramon Spaaij (2017) om de situatie in de Verenigde Staten en die in Europa te vergelijken. Het aanleggen van dergelijke databestanden stelt ons nu in staat om met grotere N's te werken: zo kwamen Gill e.a. tot 119 vooral Amerikaanse cases en het CLAT-project tot 120 gevallen in Europa. 


\section{Voorbij de status quo: kansen voor toekomstig criminologisch onderzoek}

Naast het maken van vergelijkingen tussen (sub)groepen, zoals tot op heden gedaan is, lijkt het voor toekomstig onderzoek noodzakelijk om te kijken in hoeverre vergelijkingen met andere typen gewelddadige gebeurtenissen en daders ons een beter inzicht kunnen verschaffen in het hoe, wat en waarom rond terrorisme in het algemeen, en in het bijzonder de vraag in welke mate lone actorterroristen anders zijn dan andere personen die geweld toepassen om bepaalde (persoonlijke of collectieve) doelen te bereiken (Liem e.a., 2017). Het binnenhalen van kennis uit het domein van de criminologie lijkt een zowel voor de hand liggende als potentieel waardevolle exercitie om het veld van terrorismestudies te versterken (zie ook Young \& Kearns, 2017). Dit is tot nu toe echter nog slechts mondjesmaat gedaan. Terrorismeonderzoek kan baat hebben bij een bijdrage vanuit de criminologie, en het tegenovergestelde is ook het geval. Het meer uitwisselen van empirische data zou een belangrijke stap in de goede richting zijn. En daar liggen interessante mogelijkheden.

Op het terrein van terrorismeonderzoek was lange tijd sprake van een vacuüm met betrekking tot empirisch onderzoek en een gebrek aan betrouwbare, systematische terrorismedata, maar tegelijkertijd was en is er beschikbare financiering voor onderzoek. Dit laatste heeft onderzoekers in staat gesteld terrorismedatabanken op te zetten waarmee de tekortkomingen op het onderzoeksgebied aangepakt kunnen worden. Hierbij dient te worden opgemerkt dat de enorme onderzoeksbudgetten die na 2001 beschikbaar kwamen in zekere zin ook een probleem vormen, omdat deze tot een situatie hebben geleid waarbij 'goede' data lastig van 'slechte' data te onderscheiden zijn (De Graaf, 2017). Desalniettemin hebben financieringsinstrumenten de ontwikkeling van een aantal waardevolle databanken mogelijk gemaakt. Een van de meest gebruikte datasets op dit gebied is de Global Terrorism Database (LaFree e.a., 2009; LaFree \& Dugan, 2009). Deze publiekelijk toegankelijke databank bevat data over terroristische aanslagen en baseert zich - mede gezien de problematische toegang tot data op individueel niveau - op open bronnen, zoals nieuwsberichten. Een groot voordeel van deze databank betreft de wereldwijde schaal, waarin niet alleen wordt gekeken naar transnationale terroristische aanslagen, maar waarin ook zogenaamde 'domestic' aanslagen door zowel groeperingen als eenlingen worden meegenomen.

Dit databestand en verzamelingen van specifieke typen terrorisme, waaronder lone actor-terrorisme, bieden de mogelijkheid om de kenmerken van terrorismeverdachten te vergelijken met die van andere, 'conventionele' verdachten, zoals verzameld voor criminologisch onderzoek. Gruenewald, Chermak en Freilich (2013) sloegen recent dit pad in met hun vergelijking van de kenmerken van extreemrechtse daders met die van 'gewone' moordenaars. Liem en collega's volgden met hun recente vergelijking van kenmerken van Europese lone actor-terroristen en niet-terroristische daders van moord en doodslag (Liem e.a., 2017). Ondanks de overeenkomsten tussen beide groepen gewelddadige daders dienen we bij het toepassen van criminologische theorieën en het vergelijken van databestanden echter zeer voorzichtig te zijn. 'Gewone' of 'conventionele' criminelen en terroristen zijn niet een-op-een gelijk te stellen. De eerste groep opereert vooral 
lokaal, terwijl terroristen veelal nationaal en grensoverschrijdend te werk gaan (LaFree, 2009). Daarnaast is bij terrorisme sprake van geweld waarbij het directe slachtoffer niet het doel maar een middel is om een breder publiek of specifieke doelgroep te raken. Bovendien is terrorisme nog steeds een extreem zeldzaam delict, zeker vergeleken met andere vormen van geweldscriminaliteit.

Een tweede aandachtsgebied voor toekomstig onderzoek betreft het vergelijken van terrorisme als fenomeen met andere gewelddadige uitingsvormen, zoals moord en doodslag, en (burger)oorlogen. Hoewel de hypothese dat terrorisme een relatie zou kunnen hebben met andere vormen van geweld en conflict uit de jaren zeventig stamt (Archer \& Gartner, 1976), is deze recentelijk nieuw leven ingeblazen door onder andere onderzoek door Pridemore en collega's (2008), die onderzochten wat de invloed was op de Amerikaanse moordratio na de Oklahoma Cityaanslag en de aanslagen op 11 september. Recentelijk onderzochten Kamprad en Liem (2018) in hoeverre er op globaal niveau sprake was van een relatie tussen de omvang van terroristisch geweld en het moordcijfer.

Een derde terrein waarop vergelijkingen zinvol zijn, met nadruk op lone actorterrorisme, is dat tussen de modus operandi van lone actors en die van andere criminelen. Een interessante poging hiertoe is de studie van Legault en Hendrickson (2009), die vaststelden dat terroristen relatief vaker schuldig werden bevonden aan vuurwapengerelateerde misdrijven dan andere federaal gestraften. De databestanden van Gill e.a. en die van het CLAT- en het PRIME-onderzoek zouden voor dergelijke toekomstige studies een gedegen eerste empirische basis kunnen bieden.

\section{Tot slot}

Hoewel er in de afgelopen jaren door criminologen stappen zijn gezet om de theoretische lacune betreffende het fenomeen terrorisme te dichten, is er nog veel terrein te winnen. Zo hebben de routine-activiteitentheorie, rationele-keuzemodellen en de strain-theorie bijgedragen aan het wetenschappelijke debat rond terrorisme. Er is tot op heden echter zeer weinig bekend over de empirische bruikbaarheid en toepasbaarheid van andere (klassieke) criminologische theorieën, waaronder sociale-leertheorieën, sociale-controletheorieën, levenslooptheorieën, legitimiteittheorieën en psychologische benaderingen (Freilich \& LaFree, 2015). Hierbij verdienen desistance-theorieën (zie bijvoorbeeld Cronin, 2006) nadere aandacht, niet in de laatste plaats gezien hun potentie voor contraterrorismebeleid. Hoewel er eerder empirisch onderzoek is gedaan naar de levenscyclus van terroristische groepen (Freilich e.a., 2009; Smith \& Damphousse, 2009), is het de moeite waard te exploreren in hoeverre ons begrip van desistance vanuit levensloopperspectief zowel op het niveau van de individuele terrorist als dat van terroristische groeperingen van toepassing is.

Voor een dergelijke bijdrage van de criminologische literatuur aan een breder en beter begrip van terrorisme alsook een beter contraterrorismebeleid is het van groot belang om empirische data te verzamelen. Dit geldt voor terrorisme in het algemeen en voor lone actor-terrorisme in het bijzonder. Alleen op die manier 
kunnen we onderzoekersmythes rond deze verschijnselen doorbreken. Bovendien kan onderzoek op die manier bijdragen aan zogeheten evidence-based beleid (LaFree, 2009). Op het gebied van lone actor-terrorisme zijn de eerste stappen in die richting gezet in de vorm van databestanden met de kenmerken van de daden en daders van aanslagen door eenlingen. Het is nu tijd voor terrorismeonderzoekers om samen met collega's uit andere disciplines, de criminologen voorop, zowel deze empirische als deze theoretische verdieping aan te brengen.

\section{Literatuur}

Agnew, R. (1992). Foundation for a general strain theory of crime and delinquency. Criminology, 30(1), 47-88.

Agnew, R. (2010). A general strain theory of terrorism. Theoretical Criminology, 14(2), 131-153.

Archer, D. \& Gartner, R. (1976). Violent acts and violent times: a comparative approach to postwar homicide rates. American Sociological Review, 41(6), 937-963.

Bie, J.L. de (2016). How jihadist networks operate: a grounded understanding of changing organizational structures, activities, and involvement mechanisms of jihadist networks in the Netherlands. Institute for Criminal Law and Criminology, Faculty of Law, Leiden University.

Bie, J.L. de, Poot, Ch.J. de \& Leun, J.P. van der (2015). Shifting modus operandi of jihadist foreign fighters from the Netherlands between 2000 and 2013: a crime script analysis. Terrorism and Political Violence, 27(3), 416-440.

Bovenkerk, F. \& Vermeulen, F. (2012). Engaging with violent Islamic extremism: local policies in western European cities. The Hague: Eleven International Publishers.

Chermak, S.M., Freilich, J.D., Parkin, W.S. \& Lynch, J.P. (2012). American terrorism and extremist crime data sources and selectivity bias: an investigation focusing on homicide events committed by far-right extremists. Journal of Quantitative Criminology, 28(1), 191-218.

Cohen, L.E. \& Felson, M. (1979). Social change and crime rate trends: a routine activity approach. American Sociological Review, 44(4), 588-608.

COT (2007). Lone-wolf terrorism. Case study for Work Package 3 'Citizens and governance in a knowledge-based society', TTSRL. Den Haag: Instituut Veiligheids- en Crisismanagement (COT).

Cronin, A.K. (2006). How Al-Qaida ends the decline and demise of terrorist groups. International Studies, 31(1), 7-48.

Elbers, J.M., Weggemans, D. \& Liem, M. (2016). Op vrije voeten: herintreding van maatschappelijk gevoelige ex-gedetineerden. Den Haag: Universiteit Leiden. doi: 10.13140/ RG.2.2.11933.72163.

Ellis, C., Pantucci R., Zuijdewijn, J.H.R. van, Bakker, E., Gomis, B., Palombi S. \& Smith, M. (2016). Lone actor terrorism. Royal United Services Institute for Defence and Security Studies. https://rusi.org/sites/default/files/201604_clat_final_report.pdf.

Europol. (2017). European Union terrorism situation and trend report 2017. Den Haag: Europol. www.europol.europa.eu/activities-services/main-reports/eu-terrorism-situationand-trend-report-te-sat-2017.

Freilich, J.D. \& LaFree, G. (2015). Criminological theory and terrorism: introduction to the special issue. Terrorism and Political Violence, 27(1), 1-8. 
Freilich, J.D., Chermak, S.M. \& Caspi, D. (2009). Critical events in the life trajectories of domestic extremist white supremacist groups. A case study analysis of four violent organizations. American Society of Criminology, 8(3), 497-530.

Gill, P., Horgan, J. \& Deckert, P. (2014). Bombing alone: tracing the motivations and antecedent behaviors of lone-actor terrorists. Journal of Forensic Sciences, 59(2), 425-435.

Graaf, B. de (2017). Terrorisme- en radicaliseringsstudies. Een explosief onderzoeksveld. Justitiële verkenningen, 43(3), 8-30.

Gruenewald, J., Chermak, S. \& Freilich, J.D. (2013). Distinguishing 'loner' attacks from other domestic extremist violence. A comparison of far-right homicide incident and offender characteristics. Criminology \& Public Policy, 12(1), 65-91.

Hamm, M. (2007). Terrorism as crime: from Oklahoma City to Al-Qaeda and beyond. New York: NYU Press.

Hamm, M. \& Spaaij, R. (2017). The age of lone wolf terrorism. New York: Columbia University Press.

Kamprad, A. \& Liem, M. (2019). Terror and the legitimation of violence: a cross-national analysis on the relationship between terrorism and homicide rates (in druk).

LaFree, G. (2009). Criminology's third war: special issue on terrorism and responses to terrorism. Criminology \& Public Policy, 8(3), 431-444.

LaFree, G. \& Ackerman, G. (2009). The empirica; study of terrorism: social and legal research. Annual Review of Law and Social Science, 5, 347-374.

LaFree, G. \& Dugan, L. (2009). Research on terrorism and countering terrorism. Crime and Justice, 38, 413-477.

LaFree, G. \& Gruenewald, J. (2018). The intersection of homicide, terrorism, and violent extremism. Homicide Studies, 22, 3-7.

LaFree, G., Yang, S.M. \& Crenshaw, M. (2009). Trajectories of terrorism. Attack pattern of foreign groups that have targeted the United States 1970-2004. Criminology \& Public Policy, 8(3), 445-473.

Legault, R.L. \& Hendrickson, J.C. (2009). Weapon choice and American political violence. A comparison of terrorists and other felons in federal custody. Criminology \& Public Policy, 8(3), 531-559.

Liem, M., Buuren, J. van, Zuijdewijn, J.H.R. van, Schönberger, H. \& Bakker, E. (2017). European lone actor terrorists versus 'common' homicide offenders: an empirical analysis. Homicide Studies, 2(1), 45-69.

McCauley, C. \& Moskalenko, S. (2014). Toward a profile of lone wolf terrorists: what moves an individual from radical opinion to radical action? Terrorism and Political Violence, 26(1), 69-85.

Parkin, W.S., Freilich, J.D. \& Chermak, S.M. (2010). The international implications of domestic terrorism in the United States. International Crime and Justice, 283-289.

Pridemore, W.A., Chamlin, M.B. \& Trahan, A. (2008). A test of competing hypotheses about homicide following terrorist attacks: an interrupted time series analysis of September 11 and Oklahoma City. Journal of Quantitative Criminology, 24(4), 381-396.

Roberts, B. (2007). Deterrence and WMD terrorism: calibrating its potential contributions to risk reduction. Alexandria: Institute for Defense Analysis.

Rosenfeld, R. (2014). Terrorism and criminology. In: M. Deflem (ed.). Terrorism and counter-terrorism. Criminological perspectives. New York: Elsevier (pp. 19-32).

Sageman, M. (2008). Leaderless jihad: terror networks in the twenty-first century . Philadelphia: University of Pennsylvania Press.

Schuurman, B. (2017). Becoming a European homegrown jihadist: a multilevel analysis of involvement in the Dutch Hofstadgroup, 2002-2005. Leiden: Universiteit Leiden. 
Schuurman, B. \& Eijkman, Q. (2013). Moving terrorism research forward: the crucial role of primary sources. ICCT Background note. The Hague: ICCT.

Smith, B.L. \& Damphousse, K.R. (2009). Patterns of precursor behavior in the life span of a US environmental terrorist group. Criminology \& Public Policy, 8(3), 475-496.

Smith, B.L., Damphousse, K.R., Jackson, F. \& Sellers, A. (2002). The prosecution and punishment of international terrorists in federal courts: 1980-1998. Criminology \& Public Policy, 1(3), 311-338.

Smith, B.L., Roberts, P., Gruenewald, J. \& Klein, B. (2014). Patterns of lone actor terrorism in the United States: research brief. START College Park.

Spaaij, R. (2009). The enigma of lone wolf terrorism: an assessment. Studies in Conflict and Terrorism, 33, 854-870.

Spaaij, R. (2012). Understanding Lone wolf terrorism: global patterns, motivations and prevention. Springer.

Stern, J. (2003). Terror in the name of God: why religious militants kill. New York: Ecco.

Stern, J. (2009). Strengths and limits of criminological research on terrorism. Criminology and Public Policy, 8(3), 661-665.

Striegher, J.L. (2013). Early detection of the lone wolf: advancement of counter-terrorism investigations with an absence or an abundance of information and intelligence. Journal of Policing, Intelligence and Counter Terrorism, 8(1), 35-53.

Useem, B. \& Clayton, O. (2009). Radicalization of US prisoners. Criminology and Public Policy, 8(3), 561-592.

Weimann, G. (2012). Lone wolves in cyberspace. Journal of Terrorism Research, 3(2), 75-90.

Young, J.K. \& Kearns, E.M. (2017). Empirical challenges to studying terrorism and homicide. In: F. Brookman, E. Maguire \& M. Maguire (eds.). The handbook of homicide. Chichester: Wiley Blackwell, 231-248. 